\title{
Tumor-Associated Calcium Signal Transducer 2 Is Required for the Proper Subcellular Localization of Claudin 1 and 7
}

\author{
Implications in the Pathogenesis of Gelatinous Drop-Like \\ Corneal Dystrophy
}

\author{
Mina Nakatsukasa, ${ }^{*}$ Satoshi Kawasaki, ${ }^{*}$ \\ Kenta Yamasaki, ${ }^{*}$ Hideki Fukuoka, ${ }^{*}$ \\ Akira Matsuda, ${ }^{\dagger}$ Motokazu Tsujikawa, ${ }^{\ddagger}$ \\ Hidetoshi Tanioka, ${ }^{*}$ Maho Nagata-Takaoka, ${ }^{*}$ \\ Junji Hamuro, ${ }^{*}$ and Shigeru Kinoshita* \\ From the Department of Ophthalmology, Kyoto Prefectural \\ University of Medicine, Kyoto; the Department of \\ Ophthalmology, ${ }^{\ddagger}$ Osaka University; Osaka; and the \\ Department of Ophthalmology, Juntendo University School \\ of Medicine, Tokyo, Japan
}

Gelatinous drop-like dystrophy (GDLD) is a rare autosomal recessive form of corneal dystrophy characterized by subepithelial amyloid depositions on the cornea. Previous clinical and laboratory observations have strongly suggested that epithelial barrier function is significantly decreased in GDLD. Despite the decade-old identification of the tumor-associated calcium signal transducer 2 (TACSTD2) gene as a causative gene for GDLD, the mechanism by which the loss of function of this causative gene leads to the pathological consequence of this disease remains unknown. In this study, we investigated the functional relationship between the TACSTD2 gene and epithelial barrier function. Through the use of immunoprecipitation and a proximity ligation assay, we obtained evidence that the TACSTD2 protein directly binds to claudin 1 and 7 proteins. In addition, the loss of function of the TACSTD2 gene leads to decreased expression and change in the subcellular localization of tight junction-related proteins, including claudin 1 , 4, 7, and ZO1 and occludin, both in diseased cornea and cultured corneal epithelial cells. These results indicate that loss of function of the TACSTD2 gene impairs epithelial barrier function through decreased expres- sion and altered subcellular localization of tight junction-related proteins in GDLD corneas. (Am J Pathol 2010, 177:1344-1355; DOI: 10.2353/ajpath.2010.100149)

Gelatinous drop-like corneal dystrophy (GDLD) has been reported as an uncommon, autosomal recessive disease, characterized by bilateral corneal amyloidosis. ${ }^{1}$ To date, this disease is still quite rare in many countries, whereas it is relatively common in Japan, with a prevalence rate of 1 in 31,546 estimated from the frequency of parental consanguinity. ${ }^{2,3}$ During the first decade, GDLD patients develop subepithelial nodular amyloid depositions that result in severe photophobia, lacrimation, and an ocular foreign body sensation. ${ }^{4,5}$ With age, the amyloid depositions typically enlarge, increase in number, coalesce with each other, and exhibit a mulberry-like appearance, thus leading to severe bilateral vision loss usually beginning within the third decade of their lives. The tumor-associated calcium signal transducer 2 (TACSTD2) has been identified as a causative gene for GDLD. ${ }^{6,7}$

We previously reported that the corneal epithelium of GDLD has significantly increased permeability for fluorescence $^{8}$ and horseradish peroxidase ${ }^{9}$ and that the apical side of the corneal epithelium of GDLD exhibited

Supported by a grant-in-aid (21592238) from the Japanese Ministry of Education, Science, Culture, and Sports. This work was also supported by a research fund from the Kyoto Foundation for the Promotion of Medical Science.

Accepted for publication April 29, 2010.

Supplemental material for this article can be found on http://ajp. amjpathol.org.

Address reprint requests to Satoshi Kawasaki, M.D., Ph.D., Department of Ophthalmology, Kyoto Prefectural University of Medicine, 465 Kajii-cho, Hirokoji-agaru, Kawaramachi-dori, Kamigyo-ku, Kyoto 602-0841, Japan. E-mail: bluenova@koto.kpu-m.ac.jp. 
loosened cell-to-cell junctions and an increased number of scarred cells compared with that of normal cornea. ${ }^{8}$ Furthermore, we have recently shown that the most apical side of the lateral membrane of the superficial cells did not express claudin (CLDN)1, ZO1 (tight junction protein 1 (TJP1)), and occludin (OCLN) proteins in GDLD corneas. ${ }^{10}$ These findings strongly suggest that the epithelial barrier function may be compromised in GDLD corneas, thereby allowing the formation of amyloid depositions through permeation of tear lactoferrin ${ }^{11,12}$ or apolipoprotein. ${ }^{13}$ However, the exact molecular mechanisms by which the TACSTD2 protein affects the epithelial barrier function have yet to be elucidated.

In this study, we sought to shed a light on the presumed role of the TACSTD2 gene in the epithelial barrier function. We found that the TACSTD2 protein directly binds to CLDN1 and 7 proteins and that the functional loss of the TACSTD2 gene leads to decreased expression and altered subcellular localization of the TJ-related proteins. From these findings we conclude that the loss of function of the TACSTD2 gene impairs epithelial barrier function through the functional change of the TJ-related proteins in GDLD corneas.

\section{Materials and Methods}

\section{Ethical Issues}

All experimental procedures were approved by the Institutional Review Board for Human Studies at Kyoto Prefectural University of Medicine. Prior informed consent was obtained from all patients after a detailed explanation of the study protocols, and this study was performed in accordance with the tenets of the Declaration of Helsinki for research involving human subjects.

\section{Biohazard}

For the production and the use of the lentivirus vector, we used a P2 level biohazard room after obtaining permission from the Institutional Review Board for Studies in Gene Recombination at Kyoto Prefectural University of Medicine.

\section{Antibodies}

All antibodies were raised against human antigens. Primary antibodies used in this study included anti-CLDN1 (mouse monoclonal (MM) IgG 2 , clone 1C5-D9; Abnova, Taipei, Taiwan), CLDN4 (MM IgG 1 , clone 3E2C1; Zymed Laboratories, San Francisco, CA), CLDN7 (MM IgG I $_{2}$ clone 5D10F3; Zymed Laboratories), TACSTD2 (MM $\operatorname{lgG}_{2} \mathrm{a}$, clone 77220 or goat polyclonal; R\&D Systems, Minneapolis, MN), TJP1 (MM IgG , clone ZO1-1A12; Invitrogen, Carlsbad, CA), OCLN (goat polyclonal IgG, sc8145; Santa Cruz Biotechnology, Santa Cruz, CA), desmoplakin ( $\mathrm{MM} \mathrm{IgG}_{2} \mathrm{~b}$, clone DP I/II 236.23.1; PROGEN, Heidelbrg, Germany), desmocollin (MM $\operatorname{lgG}_{1}$, clone 3G130; LifeSpan BioSciences, Seattle, WA), desmoglein (MM IgG 1 , clone G129; American Research Products, Belmont, MA), and goldin-97 (MM IgG 1 , clone CDF4;
Invitrogen Corp.). For isotype control, normal mouse $\operatorname{lgG}_{1}$ (DakoCytomation, Glostrup, Denmark), normal mouse $\operatorname{lgG}_{2}$ a (Ancell, Bayport, MN) normal mouse lgG ${ }_{2}$ b (DakoCytomation), or normal goat IgG (Santa Cruz Biotechnology) were used.

\section{Oligomers}

All oligomers used in this study were synthesized by the Invitrogen (Table 1).

\section{Tissue Preparation}

Normal corneal tissues were obtained from Northwest Lions Eye Bank (Seattle, WA). GDLD corneas ( $n=4$, all bearing a $p .118 Q>X$ mutation) were obtained at the time of penetrating keratoplasty surgery. Normal tissues were obtained from skin, pharynx, esophagus, stomach, small intestine, colon, bladder, uterine cervix, and vagina during various kinds of surgery. These tissues were embedded in optimal cutting temperature compound (Tissue-Tek OCT; Sakura Fine Technical, Tokyo, Japan) and snap-frozen with liquid nitrogen and stored in a $-80^{\circ} \mathrm{C}$ freezer.

\section{Cell Culture}

SV40 immortalized human corneal epithelial (HCE-T) cells $^{14}$ were subcultured every 4 days and maintained in Dulbecco's modified Eagle's medium/F12 containing 200 $\mathrm{U} / \mathrm{ml}$ penicillin and streptomycin, 10\% fetal bovine serum (Mediatech, Herndon, VA), $0.1 \mu \mathrm{g} / \mathrm{ml}$ cholera toxin (List Biological Laboratories, Campbell, CA), $5 \mu \mathrm{g} / \mathrm{ml}$ insulin (Sigma-Aldrich, St. Louis, MO), and $10 \mathrm{ng} / \mathrm{ml}$ human epidermal growth factor (Invitrogen). ${ }^{15}$ HeLa cells and 293T cells were subcultured every 4 days and maintained in Dulbecco's modified Eagle's medium containing 10\% fetal bovine serum. The HCE-T cells were further subcloned by a limiting dilution method as reported previously. ${ }^{16}$

\section{Laser Microdissection}

Epithelial cells were microdissected from 10- $\mu$ m-thick cryosections of GDLD or normal corneal tissues using a laser microdissection system (LMD3100; Leica, Wetzlar, Germany) to avoid any contamination by nonepithelial cells.

\section{RNA Extraction and cDNA Synthesis}

RNA was extracted from the cultured cells and the microdissected epithelial cells using a commercial columnbased extraction kit (RNeasy Mini or RNeasy Micro kit; Qiagen, Hilden, Germany). The RNAs were reverse transcribed in a buffer containing $10 \mathrm{U} / \mu$ l recombinant reverse transcriptase (Transcriptor First Strand cDNA synthesis kit; Roche Diagnostics, Mannheim, Germany) and $60 \mu \mathrm{mol} / \mathrm{L}$ of a random primer. 
Table 1. List of the Oligomers Used in This Study

\begin{tabular}{|c|c|c|c|c|}
\hline Primer & Target & Purpose & Direction & Sequence \\
\hline TACSTD2_qPCR_F & TACSTD2 & qPCR & Forward & 5'-CCTGAACGCAGTTTGGATGTC-3' \\
\hline TACSTD2_qPCR_R & & & Reverse & $5^{\prime}$-GTAAGGGCAAGCTGAAGAATAAATAGA-3' \\
\hline CLDN1_qPCR_F & CLDN1 & qPCR & Forward & 5'-CAGTCAATGCCAGGTACGAATTT-3' \\
\hline CLDN1_qPCR_R & & & Reverse & $5^{\prime}-$ AAAGTAGGGCACCTCCCAGAA-3' \\
\hline CLDN4_qPCR_F & CLDN4 & qPCR & Forward & $5^{\prime}$-GCTGGCTTGCGCATCAG-3' \\
\hline CLDN4_qPCR_R & & & Reverse & 5'-ACGGACTTAACGTTCGCAGAGT-3' \\
\hline CLDN7_qPCR_F & CLDN7 & qPCR & Forward & $5^{\prime}-$ ACAAAGTGAAGAAGGCCCGTATAG- $3^{\prime}$ \\
\hline CLDN7_qPCR_R & & & Reverse & $5^{\prime}$ - GCTACCAAGGCGGCAAGAC- $3^{\prime}$ \\
\hline TACSTD̄2_exp_F & TACSTD2 & Expression & Forward & 5'-TTCCTCCGCCCCACCATGGCTC-3' \\
\hline TACSTD2_exp_R & & & Reverse & $5^{\prime}$-GTAGGTACCCGGCGGGGCAG-3' \\
\hline CLDN1_exp_F'- & CLDN1 & Expression & Forward & 5'-CGAGTCATGGCCAACnGCGGGGCTG-3' \\
\hline CLDN1_exp_R & & & Reverse & 5'-CTTTTGCCTCTGTGTCACACGTAG-3' \\
\hline CLDN4_exp_F & CLDN4 & Expression & Forward & 5'-CTGAACAATGGCCTCCATGGGGCTA-3' \\
\hline CLDN4_exp_R & & & Reverse & 5'-GAGGAACAGAGTGGAGCCGTGGCAC-3' \\
\hline CLDN7_exp_F & CLDN7 & Expression & Forward & $5^{\prime}$-GGCGGAAATGGCCAATTCGGGCCTG-3' \\
\hline CLDN7_exp_R & & & Reverse & 5'-GCCTGTCAGGCTGGGGCAAGGAGAT-3' \\
\hline TACSTD̄2_shRNA_1_F & TACSTD2 & shRNA & Forward & $\begin{array}{l}\text { 5'-CCGGCGTGGACAACGATGGCCTCTACTC } \\
\text { GAGTAGAGGCCATCGTTGTCCACGTTTTTG-3' }\end{array}$ \\
\hline TACSTD2_shRNA_1_R & & & Reverse & 5'-AATTCAAAAACGTGGACAACGATGGCCTCT \\
\hline & & & & ACTCGAGTAGAGGCCATCGTTGTCCACG-3' \\
\hline TACSTD2_shRNA_3_F & TACSTD2 & shRNA & Forward & $\begin{array}{l}5^{\prime} \text {-CCGGCTACTTCGAGAGGGACATCAAC } \\
\text { TCGAGTTGATGTCCCTCTCGAAGTAGTTTTTG-3' }\end{array}$ \\
\hline TACSTD2_shRNA_3_R & & & Reverse & $\begin{array}{l}5^{\prime} \text { - AATTCAAAAACTACTTCGAGAGGGACAT } \\
\text { CAACTCGAGTTGATGTCCCTCTCGAAGTAG-3' }\end{array}$ \\
\hline CLDN1_shRNA_1_F & CLDN1 & shRNA & Forward & $\begin{array}{l}5^{\prime} \text {-CCGGGCAAAGTCTTTGACTCCTTGCCTCG } \\
\text { AGGCAAGGAGTCAAAGACTTTGCTTTTTG-3' }\end{array}$ \\
\hline CLDN1_shRNA_1_R & & & Reverse & $\begin{array}{l}5^{\prime}-\text { AATTCAAAAAGCAAAGTCTTTGACTCCTT } \\
\text { GCCTCGAGGCAAGGAGTCAAAGACTTTGC-3' }\end{array}$ \\
\hline CLDN1_shRNA_4_F & CLDN1 & shRNA & Forward & $\begin{array}{c}\text { 5'-CCGGGCCACAAGACCTAGCCTAATTCTCGA } \\
\text { GAATTAGGCTAGGTCTTGTGGCTTTTTG-3' }\end{array}$ \\
\hline CLDN1_shRNA_4_R & & & Reverse & $\begin{array}{l}\text { 5'-AATTCAAAAAGCCACAAGACCTAGCCTAATT } \\
\text { CTCGAGAATTAGGCTAGGTCTTGTGGC-3' }\end{array}$ \\
\hline CLDN1_shRNA_6_F & CLDN1 & shRNA & Forward & $\begin{array}{l}\text { 5'-CCGGGCATCGTTATTAAGCCCTTATCTC } \\
\text { GAGATAAGGGCTTAATAACGATGCTTTTTG-3' }\end{array}$ \\
\hline CLDN1_shRNA_6_R & & & Reverse & $\begin{array}{l}5^{\prime} \text {-AATTCAAAAAGCATCGTTATTAAGCCCTTATC } \\
\text { TCGAGATAAGGGCTTAATAACGATGC-3' }\end{array}$ \\
\hline CLDN4_shRNA_1_F & CLDN4 & shRNA & Forward & $\begin{array}{l}\text { 5'-CCGGGCAACATTGTCACCTCGCAGACTC } \\
\text { GAGTCTGCGAGGTGACAATGTTGCTTTTTG-3' }\end{array}$ \\
\hline CLDN4_shRNA_1_R & & & Reverse & $\begin{array}{l}\text { 5'-AATTCAAAAAGCAACATTGTCACCTCGCAGA } \\
\text { CTCGAGTCTGCGAGGTGACAATGTTGC-3' }\end{array}$ \\
\hline CLDN4_shRNA_3_F & CLDN4 & shRNA & Forward & $\begin{array}{l}\text { 5' - CCGGCCACAACATCATCCAAGACTTCTCGA } \\
\text { GAAGTCTTGGATGATGTTGTGGTTTTTG-3' }\end{array}$ \\
\hline CLDN4_shRNA_3_R & & & Reverse & $\begin{array}{l}\text { 5'-AATTCAAAAACCACAACATCATCCAAGAC } \\
\text { TTCTCGAGAAGTCTTGGATGATGTTGTGG-3' }\end{array}$ \\
\hline CLDN4_shRNA_4_F & CLDN4 & shRNA & Forward & $\begin{array}{l}\text { 5' - CCGGCCAAGTATTCTGCTGCCCGCTCTC } \\
\text { GAGAGCGGGCAGCAGAATACTTGGTTTTTG-3' }\end{array}$ \\
\hline CLDN4_shRNA_4_R & & & Reverse & $\begin{array}{l}\text { 5'-AATTCAAAAACCAAGTATTCTGCTGCCC } \\
\text { GCTCTCGAGAGCGGGCAGCAGAATACTTGG-3' }\end{array}$ \\
\hline CLDN7_shRNA_1_F & CLDN7 & shRNA & Forward & $\begin{array}{l}\text { 5'-CCGGGAGCTCCTATGCGGGTGACAACTC } \\
\text { GAGTTGTCACCCGCATAGGAGCTCTTTTTG-3' }\end{array}$ \\
\hline CLDN7_shRNA_1_R & & & Reverse & $\begin{array}{l}\text { 5' - AATTGAGCTCCTATGCGGGTGACAACTCG } \\
\text { AGTTGTCACCCGCATAGGAGCTCTTTTTG-3' }\end{array}$ \\
\hline CLDN7_shRNA_3_F & CLDN7 & shRNA & Forward & $\begin{array}{l}\text { 5' - CCGGCCATCAGATTGTCACAGACTTCTCG } \\
\text { AGAAGTCTGTGACAATCTGATGGTTTTTG-3' }\end{array}$ \\
\hline CLDN7_shRNA_3_R & & & Reverse & $\begin{array}{l}5^{\prime} \text { - AATTCAAAAACCATCAGATTGTCACAGAC } \\
\text { TTCTCGAGAAGTCTGTGACAATCTGATGG-3' }\end{array}$ \\
\hline CLDN7_shRNA_4_F & CLDN7 & shRNA & Forward & $\begin{array}{l}\text { 5'-CCGGCCCTTTGATCCCTACCAACATCTCG } \\
\text { AGATGTTGGTAGGGATCAAAGGGTTTTTG-3' }\end{array}$ \\
\hline CLDN7_shRNA_4_R & & & Reverse & $\begin{array}{l}\text { 5'-AATTCAAAAACCCTTTGATCCCTACCAACA } \\
\text { TCTCGAGATGTTGGTAGGGATCAAAGGG-3' }\end{array}$ \\
\hline pLKO_seq_F & pLKO.1 & Sequencing & Forward & 5'-TTTCTTGGGTAGTTTGCAGTTTT-3' \\
\hline pLKO_seq_R & & & Reverse & 5'-АСТАTTCTTTCCCCTGCACTGT-3' \\
\hline CMV_seq_F & pLenti6.3 & Sequencing & Forward & 5'-CGCAAATGGGCGGTAGGCGTG-3' \\
\hline V5_seq_R & & & Reverse & $5^{\prime}$-ACCGAGGAGAGGGTTAGGGAT-3' \\
\hline TACSTD2_seq_3_F & TACSTD2 & Sequencing & Forward & 5'-CCTGCAGACCATCCCAGACG-3' \\
\hline TACSTD2_seq_3_R & & & Reverse & $5^{\prime}$-CAGGAAGCGTGACTCACTTG-3' \\
\hline
\end{tabular}




\section{Quantitative PCR}

Quantitative PCR (qPCR) was performed using a realtime PCR machine (ABI Prism 7000 Sequence Detection System; Applied Biosystems, Foster City, CA) according to the manufacturer's guidelines. Briefly, cDNAs were amplified using $10 \mathrm{pmol}$ of primer pairs designed for each purpose in a $20-\mu$ l reaction buffer containing a $2 \times$ reaction mix (Power SYBR Green PCR Master Mix; Applied Biosystems). The thermal cycle was 40 cycles of denaturation-annealing/elongation steps at $95^{\circ} \mathrm{C}$ and $60^{\circ} \mathrm{C}$, respectively. The relative expression of each gene in each sample was calculated by the formula $2^{\text {(Ct_GAPDH - Ct_gene) }}$, where the Ct_GAPDH is the cycle over the threshold for the GAPDH gene and the Ct_gene is the cycle over the threshold for each of the specific genes.

\section{Sequencing Analysis}

Sequencing analysis was performed using a commercial kit (BigDye 3.1; Applied Biosystems). Briefly, the PCR product or plasmid DNA was bidirectionally sequenced in a $20-\mu$ l reaction buffer containing a $2 \times$ sequencing mixture and a primer designed for each purpose. After ethanol precipitation, the sequence products were electrophoresed on an automated capillary sequencer (Gene analyzer 3130xl; Applied Biosystems).

\section{Short Hairpin RNA Vector Construction}

For the construction of the lentivirus plasmid vector that expresses short hairpin RNA (shRNA), we used a commercial lentiviral vector ( $p L K O .1$; Sigma-Aldrich). Briefly, pairs of oligomers designed for shRNA expression were annealed and ligated into the Agel/EcoRl-digested lentivirus plasmid vector.

\section{Expression Vector Construction}

For the construction of the lentivirus plasmid vector that expresses a gene of interest, we used a commercial lentiviral vector (pLenti6.3_V5-TOPO; Invitrogen). Briefly, cDNAs were amplified with a primer pair encompassing an entire coding sequence of a specific gene, gel-purified, and ligated into the lentivirus plasmid vector.

\section{Transformation, Propagation, and Plasmid Extraction}

The recombinant plasmid vector for either shRNA or protein expression was transformed into competent Escherichia coli cells (Competent high JM109; Toyobo, Osaka, Japan), plated on an Luria-Bertani-agar plate, propagated overnight, screened by colony-direct PCR, and then sequenced. The clone that was confirmed to have a non-mutated insert was largely propagated in a liquid Luria-Bertani medium and its harboring plasmid DNA was extracted using a commercial, transfection-grade, column-based extraction kit (NucleoBond; Macherey-Nagel, Düren, Germany).

\section{Lentivirus Production and Infection}

The 293T cells were seeded on a gelatin-coated T25 plastic flask at a density of 40,000 cells $/ \mathrm{cm}^{2}$. The lentivirus plasmid DNA (1750 ng) was transfected to the 293T cells along with an equal amount of packaging plasmid mixture (MISSION Lentiviral Packaging Mix; Sigma-Aldrich), which contains pMISSIONgagpol and pMISSIONvsvg, respectively encoding gag/pol and env virus proteins using $12 \mu \mathrm{l}$ of a commercial transfection reagent (Fugene HD; Roche Diagnostics). Two days after the transfection, the culture supernatant containing the infection-competent virus particle was harvested. The supernatant was applied onto the HCE-T cells or the HeLa cells in the presence of 10 to $20 \mu \mathrm{g} / \mathrm{ml}$ polybrene.

\section{Immunostaining Analysis}

Tissue sections placed on glass slides or cells grown on a commercial culture-glass slide (Nunc Lab-Tek Chamber Slide System; Thermo Fisher Scientific, Rochester, NY) were fixed with Zamboni fixative or 95\% ice-cold ethanol, blocked with $1 \%$ skim milk, and then incubated overnight with a primary antibody at $4^{\circ} \mathrm{C}$. After being washed with $0.01 \mathrm{M} \mathrm{PBS}$, the samples were incubated with a secondary antibody (Alexa Fluor 488-labeled antimouse or anti-goat IgG; Invitrogen) at room temperature for 1 hour. After being washed again with 0.01 M PBS, the sections or the cells were counterstained with propidium iodide, mounted, covered with coverslips, and observed and photographed by use of a fluorescence microscope (AX70 TRF; Olympus, Tokyo, Japan) or a confocal laser scanning microscope (TCS-SP2; Leica). For all experiments, we performed control experiments using isotypenegative controls corresponding to each of the primary antibodies.

\section{Measurement of Transepithelial Resistance}

HCE-T cells were cultured in a 12-well Transwell (12-mm Transwell with a 0.4- $\mu \mathrm{m}$ Pore Polyester Membrane Insert; Corning, Corning, NY). Resistance between upper and lower chambers of the Transwell was measured with the use of a volt-ohm meter (EVOM; World Precision Instruments, Sarasota, FL), and transepithelial resistance (TER) was calculated by multiplying the measured resistance (ohm) by the growth area of the Transwell filter (1.12 $\mathrm{cm}^{2}$ ). The background resistance due to the filter alone was subtracted from each of the obtained data.

\section{Immunoelectron Microscopy}

The postembedding labeling method was used to analyze the ultramicroscopic distribution of the TACSTD2 protein. Human corneal tissues were fixed in $4 \%$ paraformaldehyde at room temperature for 1 hour. After being 
washed in $0.1 \mathrm{M}$ PBS, the tissues were dehydrated through an ethanol series (50, 70, 80, 90, 95, and 100\%), then absolute ethanol, and finally through a 50:50 mixture of absolute ethanol and acrylic resin (LR White; London Resin, Reading, UK). The tissues were then embedded in LR White. Ultrathin sections $(100 \mathrm{nmol} / \mathrm{L})$ were cut on an ultratome and submitted to immunogold electron microscopy. The sections were incubated with $20 \%$ bovine serum albumin-PBS at room temperature for 20 minutes, incubated overnight with a primary antibody (goat polyclonal anti-TACSTD2) at $4^{\circ} \mathrm{C}$, washed in PBS, incubated with secondary antibody (Rabbit anti-goat IgG $(\mathrm{H}+\mathrm{L})$ Gold 10 nm; British BioCell International, Cardiff, UK) at room temperature for 2 hours, and then examined ultramicroscopically by use of an electron microscope (H7000; Hitachi, Tokyo, Japan).

\section{Immunoprecipitation Assay}

The HCE-T cells were lysed in a buffer containing 10 $\mathrm{mmol} / \mathrm{L}$ Tris- $\mathrm{HCl}, \mathrm{pH} 7.4,150 \mathrm{mmol} / \mathrm{L} \mathrm{NaCl}, 1 \%$ Triton $\mathrm{X}-100,0.5 \mathrm{mmol} / \mathrm{L}$ EDTA, and a protease inhibitor mixture (Complete Mini; Roche Diagnostics). The lysate was precleared overnight with a 1/40 volume of protein $A$ or G-sepharose (GE Healthcare UK, Buckinghamshire, UK) at $4^{\circ} \mathrm{C}$, incubated at $4^{\circ} \mathrm{C}$ for 1 hour with a mouse monoclonal or a goat polyclonal antibody against the TACSTD2 protein, and then incubated again for 1 hour with the protein A- or G-sepharose. The captured immune complex was washed four times with the ice-cold lysis buffer. The immunoprecipitates were resuspended in Laemmli sample buffer, boiled for 5 minutes, and then subjected to Western blot analysis.

\section{Western Blot Analysis}

Proteins were separated with a commercially available 4 to $20 \%$ gradient SDS-polyacrylamide gel (Invitrogen) and transferred to a polyvinylidene difluoride membrane (FluoroTrans-W; Nihon Pall, Tokyo, Japan). The membrane was blocked in a Tris-buffered saline containing $1 \%$ skim milk and $0.05 \%$ Tween 20 and incubated overnight with primary antibodies at $4^{\circ} \mathrm{C}$. After the washes, the membrane was incubated with a horseradish peroxidase-conjugated secondary antibody at room temperature for 1 hour. A chemiluminescent reagent (ECL Advance Western Blotting Detection Kit; GE Healthcare UK) was applied onto the membrane and its luminescent signal was detected by a chilled charge-coupled device camera (LAS-3000UVmini; Fujifilm, Tokyo, Japan).

\section{Proximity Ligation Assay}

In situ proximity ligation assay (PLA) analysis was performed to determine a molecular proximity between two proteins using a commercial kit (Duolink in situ PLA; Olink Bioscience, Uppsala, Sweden). Briefly, $10 \mu \mathrm{m}$ cryosections were fixed with Zamboni fixative and immersed in a blocking solution. Then, the sections were incubated overnight at $4^{\circ} \mathrm{C}$ with a pair of primary antibodies against two proteins raised from two different animals (eg, mouse versus goat). Then, the sections were incubated with a mixture of two secondary antibodies, respectively, labeled with two single-stranded DNA that are complementary to each other. The sections were then incubated first in a hybridization buffer, then in a ligation mixture, then in an amplification mixture, and finally in a detection mixture. After being washed with standard saline citrate buffer, the slides were air-dried, mounted, and observed by fluorescence microscopy.

\section{Results}

\section{Tissue Localization of the TACSTD2 Protein}

In the normal corneal epithelium, the TACSTD2 protein was found to be clearly localized at the cell-to-cell borders of all epithelial layers (Figure 1A). Also, in other stratified epithelia-type tissues such as conjunctiva (Figure 1B), skin (Figure 1C), pharynx (Figure 1D), esophagus (Figure 1E), uterine cervix (Figure 1J), and vagina (Figure $1 \mathrm{~K}$ ), the identical expression patterns were obtained. However, the TACSTD2 protein was not expressed in simple epithelia-type tissues such as stomach (Figure 1F), small intestine (Figure 1G), and colon (Figure $1 \mathrm{H}$ ) or in the transitional epithelia-type tissue such as bladder (Figure 1I). Negative isotype control (normal mouse $\lg _{2}$ a) produced virtually no fluorescent signal in any of the tissues (Figure 1L, supplemental Figure 1, A-K, see http://ajp.amjpathol.org).
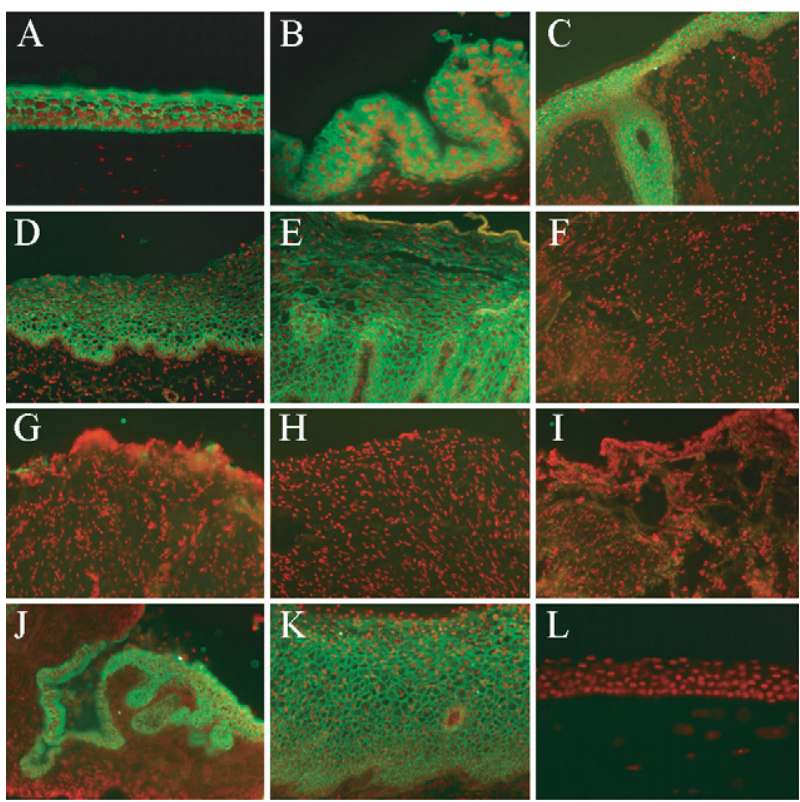

Figure 1. Expression of the TACSTD2 protein in cornea (A), conjunctiva (B) skin $(\mathbf{C})$, pharynx (D), esophagus $(\mathbf{E})$, stomach $(\mathbf{F})$, small intestine $(\mathbf{G})$, colon $(\mathbf{H})$, bladder (I), uterine cortex $(\mathbf{J})$, and vagina $(\mathbf{K})$. For negative control, normal cornea was immunostained with normal mouse IgG1 or IgG2a. L: Green indicates the signal for the TACSTD2 protein and red indicates the signal for propidium iodide. Original magnification was $\times 20(\mathbf{C}-\mathbf{K})$ or $\times 40$ $(\mathbf{A}, \mathbf{B}$, and $\mathbf{L})$. 
A

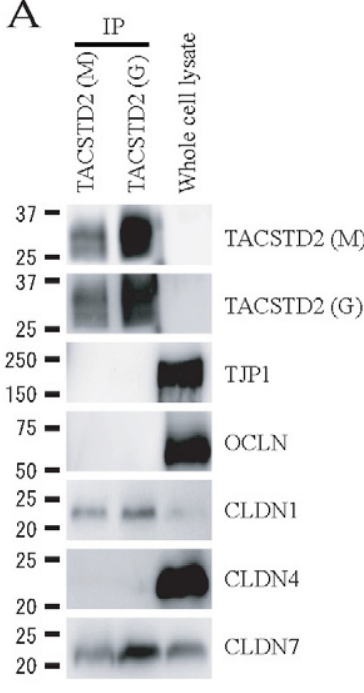

B
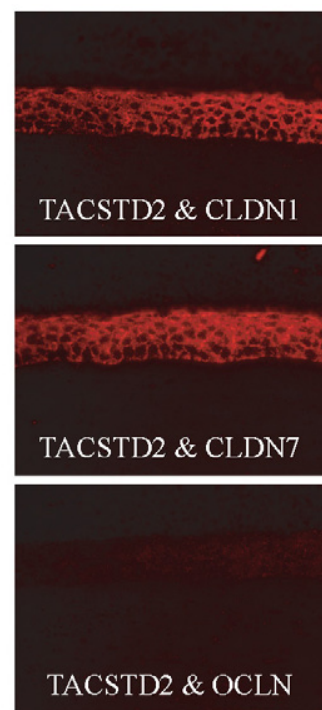

$\mathrm{C}$

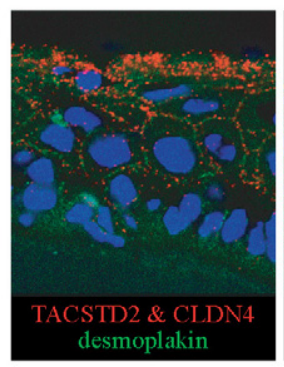

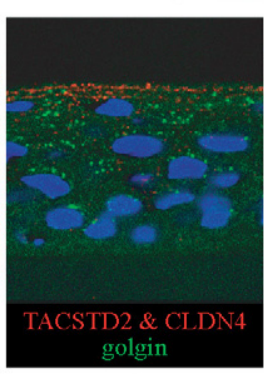

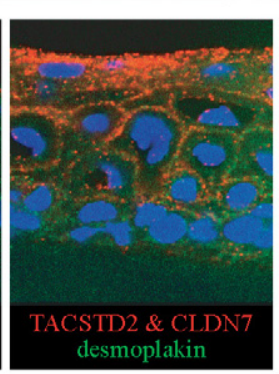

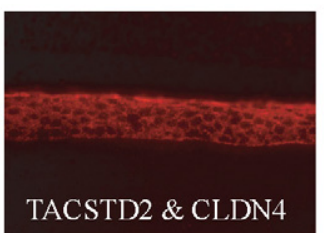
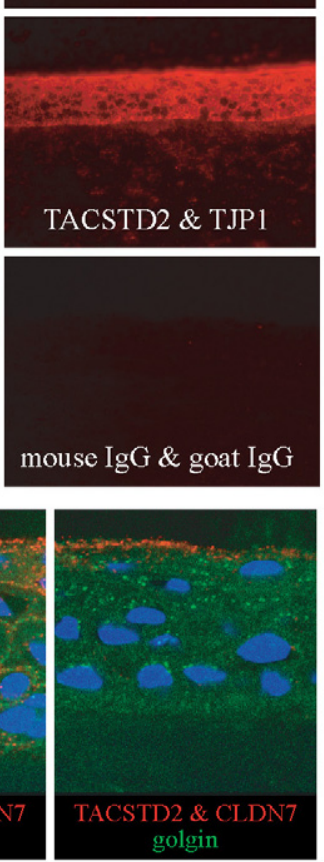

Figure 2. Relationship between the TACSTD2 protein and TJ-related proteins. A: HCE-T-15 cells were lysed and immunoprecipitated using an anti-TACSTD2 antibody that was raised in a mouse (M) or goat (G). The immunoprecipitants were electrophoresed and immunoblotted using antibodies against the indicated proteins. B: PLA analysis was performed on normal corneal tissue using pairs of antibodies against the TACSTD2 and the CLDN1, 4, 7, TJP1, and OCLN proteins. For a negative control, PLA analysis was performed using normal mouse $\operatorname{IgG}\left(\operatorname{IgG}_{1}\right.$ or $\operatorname{IgG}_{2}$ a) and normal goat IgG. Original magnification was $\times 40$. C: PLA analysis was performed using pairs of antibodies against the TACSTD2 and the CLDN 4 or 7 proteins and further immunostained with antibody against desmoplakin or golgin. Red indicates PLA signal, green indicates the signal of desmoplakin or golgin, and blue indicates nucleus stained with $4^{\prime}, 6^{\prime}$-diamidino-2phenylindole. Original magnification was $\times 252$.

\section{Direct Binding of the TACSTD2 Protein to CLDN1 and 7 Proteins}

Previously it was reported that TACSTD2 and EpCAM proteins are serologically similar, ${ }^{17,18}$ and our BLAST homology search revealed that the EpCAM gene is the gene most similar to the TACSTD2 gene, with $48 \%$ identity over a range of $1500 \mathrm{bp}$. The EpCAM protein has been reported to directly bind to the CLDN7 protein, and acts cooperatively with this TJ-related protein in tumor progression. ${ }^{19-21}$ Therefore, we hypothesized that the TACSTD2 protein is spatially and functionally associated with the TJ apparatus. To verify that hypothesis, we first investigated whether the TACSTD2 protein binds to the CLDN proteins in HCE-T cells. We had identified a HCE-T subclone, HCE-T-15, which shows high epithelial barrier function ${ }^{16}$ and express the same set of TJ-related proteins as corneal epithelium in vivo. ${ }^{22}$ We used this cell line for following experiments.

Immunoprecipitation assay clearly demonstrated that the TACSTD2 protein binds to the CLDN1 and 7 proteins (Figure 2A) in the HCE-T-15 cells. The binding affinity seems relatively higher in the TACSTD2/CLDN7 complex than in the TACSTD2/CLDN1 complex. On the other hand, other TJ-related proteins such as the CLDN4, TJP1, and OCLN proteins were not coimmunoprecipitated with the TACSTD2 proteins. The immunoprecipitation experiments with varying concentrations of detergent revealed that the CLDN4, TJP1, and OCLN proteins were not coimmunoprecipitated in any of the detergent concentrations examined (data not shown).
To examination protein interaction in vivo, we performed the in situ PLA analysis using the normal corneal tissues. Positive signals were obtained between the TACSTD2 protein and either of the CLDN1, CLDN4, CLDN7, and TJP1 proteins, while no significant signal was detected between the TACSTD2 and OCLN proteins (Figure 2B). In the PLA experiment plus immunolabeling using a fluorescence-labeled antibody against desmoplakin or golgin, most of the PLA signals fall onto the plasma membrane, but only a trace amount in cytoplasm (Figure 2C). Virtually no signals were localized to the Golgi apparatus (Figure 2C). These results indicate that the association between the TACSTD2 and the CLDN proteins mainly occurred at the plasma membrane.

\section{Decrease of Epithelial Barrier Function by the Knockdown of the TACSTD2 Gene}

Next, we investigated whether the clinically observed decrease in epithelial barrier function is really a direct consequence of the ablation of the TACSTD2 gene. We constructed five lentiviral vectors expressing shRNA against the TACSTD2 gene, of which two vectors (shRNATACSTD2-1, 3) were found to successfully down-regulate expression of the TACSTD2 gene both in mRNA and protein level in the HCE-T-15 cells (Figure 3, A and B). The HCE$\mathrm{T}-15$ cells infected with either of these two vectors demonstrated a significantly low TER value over a 1-week period compared with their cognate controls (Figure 3C). Next, we investigated whether the knockdown of the TACSTD2 gene 
A

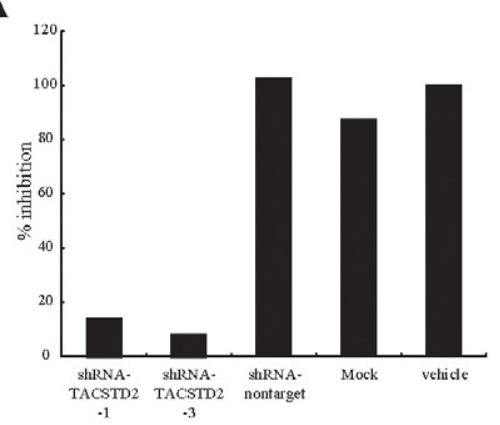

B

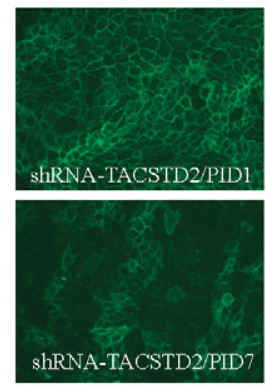

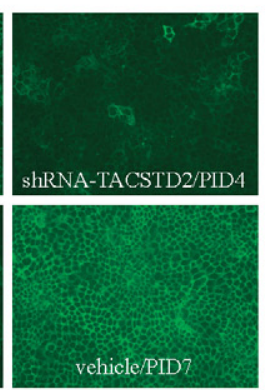

C

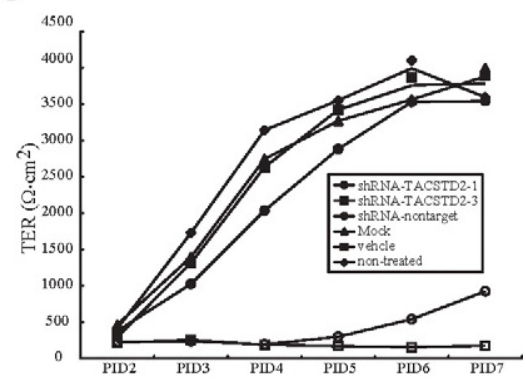

D anti-CLDN1

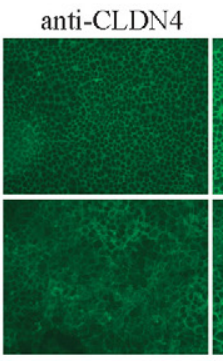

anti-CLDN7

anti-OCLN

anti-TJP1
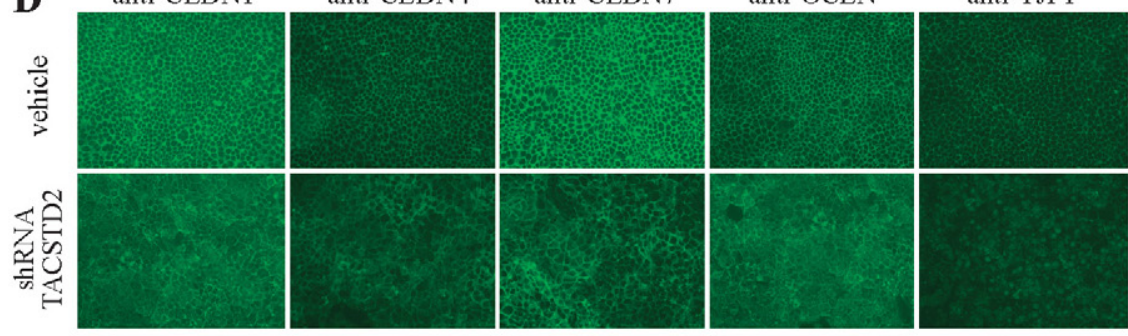

E
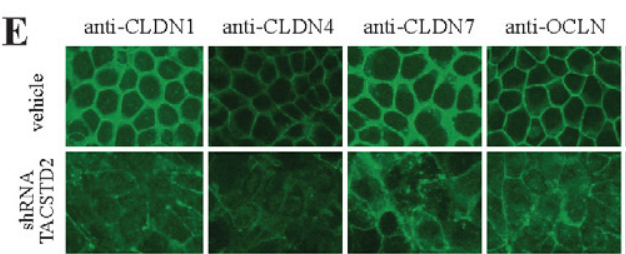

anti-TJP1

F
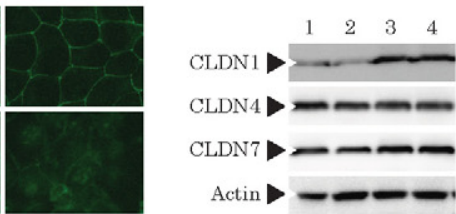

Figure 3. Knockdown of the TACSTD2 gene leads to decreased epithelial barrier function accompanied with change in expression level and subcellular localization of the TJ-related proteins in HCE-T-15 cells. A: Effect of the lentiviral introduction of shRNA vectors against the TACSTD2 gene on the expression of the TACSTD2 gene. The vertical bar indicates the percentile inhibition of the TACSTD2 mRNA where expression of vehicle was set to 100\%. Compared with the controls (shRNA-nontarget, mock, vehicle), two shRNA vectors against the TACSTD2 gene significantly down-regulated TACSTD2 mRNA at PID 4 . B: Effect of the lentiviral introduction of shRNA vectors against the TACSTD2 gene on the expression of the TACSTD2 protein at PID 1, 4, and 7 in the HCE-T-15 cells. Compared with the vehicle at PID 7, the expression level of the TACSTD2 protein was gradually decreased day by day in the shRNA-introduced HCE-T- 15 cells. Original magnification was $\times 40$. C: Effect of the lentiviral introduction of shRNA vectors against the TACSTD2 gene on the epithelial barrier function in HCE-T-15 cells. The horizontal bar indicates the number of days postinfection (PID) and the vertical bar indicates TER in $\Omega \cdot \mathrm{cm}^{2}$. D: Effect of the lentiviral introduction of shRNA vector against the TACSTD2 gene on the expression of the CLDN1, CLDN4, CLDN7, OCLN, and TJP1 proteins. Compared with the vehicle, the shRNA-introduced HCE-T-15 cells exhibited the decreased expression in the CLDN1 and seven proteins and altered subcellular localization from plasma membrane to cytoplasm or nucleus in all of those TJ-related proteins. Original magnification was $\times 40$. E: Magnified images of $\mathbf{D}$ to indicate the subcellular localization of the TJ-related proteins. F: Results of Western blot analysis to examine the effect of shRNA introduction on the expression of the CLDN1, CLDN4, and CLDN7 proteins. The expression levels of the CLDN1 and seven proteins were decreased in the HCE-T-15 cells introduced with shRNA against the TACSTD2 gene (lane 1, shRNA-TACSTD2-1; lane 2, shRNA-TACSTD2-3) compared with the HCE-T-15 cells introduced with shRNA-nontarget (lane 3) or mock vector (lane 4). "shRNA-nontarget" means that the lentiviral vector expressing shRNA, which was designed to have no interference with any human genes. "Mock" means the lentiviral vector without an shRNA cassette. "Vehicle" means absence of lentiviral vector infection but presence of the treatment with the same concentration of polybrene for the same period. "Nontreated" means absence of lentiviral infection as well as polybrene treatment.

in the HCE-T-15 cells has any effect on the expression of TJ-related proteins. Seven days after the infection, we found that the expression levels of the CLDN1 and 7 proteins were significantly decreased (Figure 3, D-F). In addition, the subcellular localization appeared to be changed from plasma membrane to cytoplasm in CLDN1, 4, and 7, and OCLN, and from plasma membrane to nucleus in the TJP1 protein (Figure 3, D and E).

\section{Decrease of Epithelial Barrier Function by Knockdown of Either of the CLDN1, 4, and 7 Proteins}

We next investigated whether the reduced expression and/or altered subcellular localization of the CLDN1, 4, and 7 proteins caused by the knockdown of the TACSTD2 gene in the HCE-T-15 cells has any effects on the epithelial barrier function. We knocked down either of the CLDN1,
4, and 7 genes in the HCE-T-15 cells by the introduction of shRNA expressing lentiviral vectors, all of which were found to successfully knock down mRNA of these genes (Figure 4, A-C). As expected, although the level of the decrease varied by gene, knockdown of all of those CLDN genes produced a significantly decreased TER value compared with their cognate controls (Figure 4, D-F).

\section{TACSTD2 Protein Is Required for High Level Expression of the CLDN1 and 7 Proteins but Not for That of the CLDN4 Protein}

The epithelial barrier function generally differs by the type of epithelial cells. HeLa cells demonstrated significantly Iow TER values even 2 weeks after they reached confluence (Figure 5A). In agreement with this observation, the endogenous expression level of the TACSTD2 protein, as 
A

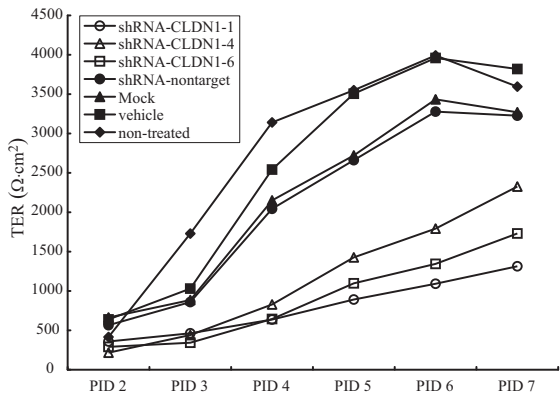

$\mathrm{C}$

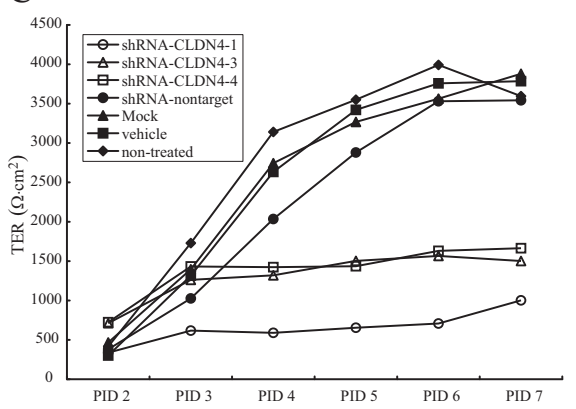

E

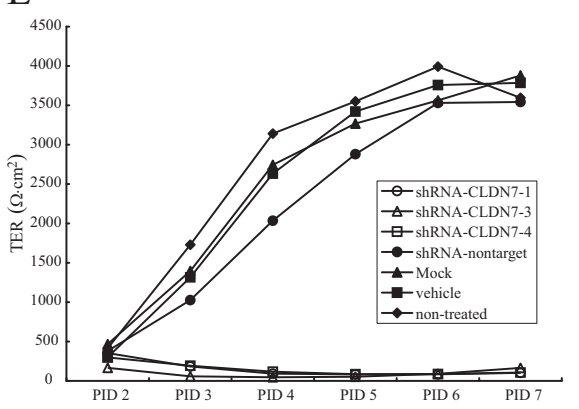

B

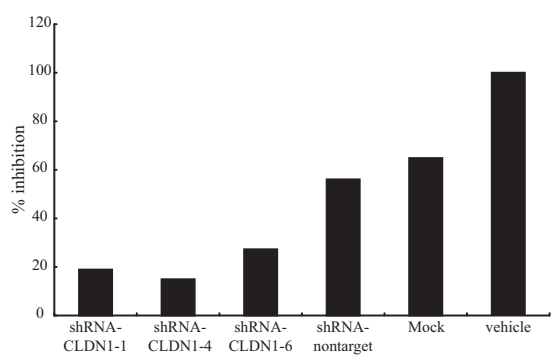

D

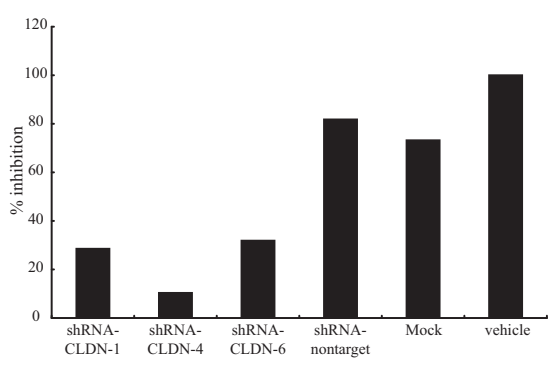

$\mathrm{F}$

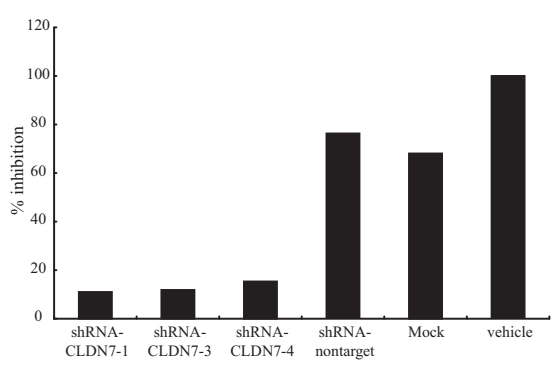

Figure 4. Knockdown of either of the CLDN1, 4 , and 7 proteins significantly decreased the epithelial barrier function in the HCE-T-15 cells. HCE-T-15 cells were infected with lentiviral vectors expressing shRNA against the CLDN1 (A and B), $4(\mathbf{C}$ and $\mathbf{D})$, and 7 (E and $\mathbf{F})$ proteins. TER (A, C, and E) was measured up to seven days after the infection. The vertical bars indicate TER in $\Omega \cdot \mathrm{cm}^{2}$. The horizontal bars indicate PID. Bar graphs $(\mathbf{B}, \mathbf{D}$, and $\mathbf{F})$ demonstrate the effect of the lentiviral introduction of shRNA vectors on the expression of those genes. Vertical bar indicates the percentile inhibition of those mRNA where expression of the vehicle was set to $100 \%$ Compared with the controls (shRNA-nontarget, mock, vehicle), for each of those genes, three shRNA vectors significantly down-regulated mRNA of their target at PID4. well as the CLDN4 and 7 proteins, was significantly lower in HeLa cells than in HCE-T-15 cells (Figure 5B). HeLa cells were transfected with each of the lentiviral vectors expressing the CLDN1, 4, and 7 proteins. The expression level of the CLDN1 and 7 proteins was significantly lower than that of the CLDN4 protein and the subcellular localization of the CLDN1 and 7 proteins was virtually restricted to the perinuclear zone (Figure 5C). However, when HeLa cells were cotransfected with the lentiviral vectors expressing the TACSTD2 protein, the expression level of the CLDN1 and 7 proteins significantly recovered to a level as high as that of the CLDN4 protein, while the expression level of the CLDN4 protein was almost unchanged (Figure 5C). In addition, at least a recognizable amount of the CLDN1 and 7 proteins were distributed to the plasma membrane, as was found with the CLDN4 protein. These results suggest that higher expression and membrane distribution of the CLDN1 and 7 proteins require the expression of the TACSTD2 protein but the CLDN4 protein is independent of the expression of the TACSTD2 protein. This seems to be in good agreement with our immunoprecipitation results that the CLDN1 and 7 proteins bound to the TACSTD2 protein, while the CLDN4 protein did not.

\section{TACSTD2 Protein Protects CLDN1 and 7 Proteins from the Degradation by the Ubiquitin-Proteasome System}

We further investigated which mechanism causes the reduced expression of the CLDN1 and 7 proteins in the absence of the TACSTD2 protein. HeLa cells transfected with lentiviral vectors expressing CLDN1, 4, or 7 were treated with proteasome inhibitor MG-132 for 24 hours. The MG-132 treatment significantly increased the expression level of the CLDN1 and 7 proteins but had virtually no effect on the expression level of the CLDN4 protein (Figure 5, D and E). These results suggest that the TACSTD2 protein enhances the stability of the CLDN1 and 7 proteins and protects them from degradation via the ubiquitin-proteasome system.

\section{Down-Regulation and Altered Subcellular Localization of TJ-Related Proteins in GDLD Corneas}

Next, we examined the expression of the TACSTD2 and TJ-related proteins in the normal and GDLD corneas 
A

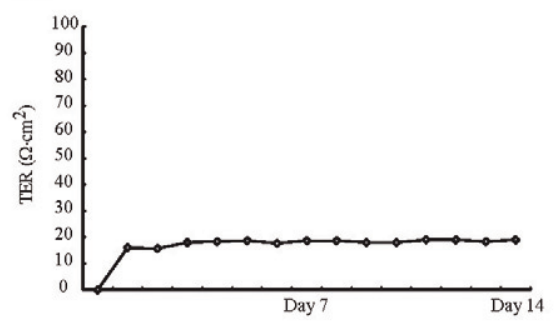

$\mathrm{C}$

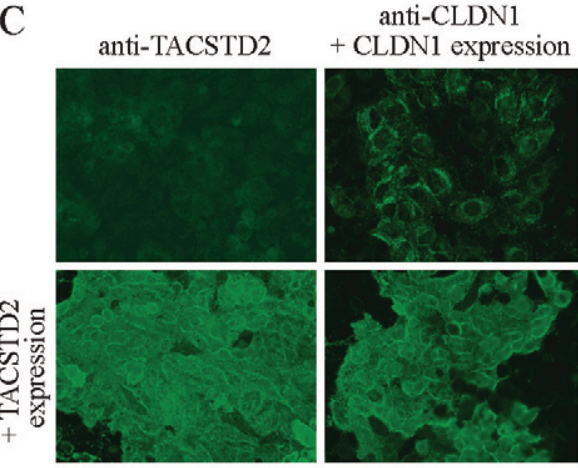

D

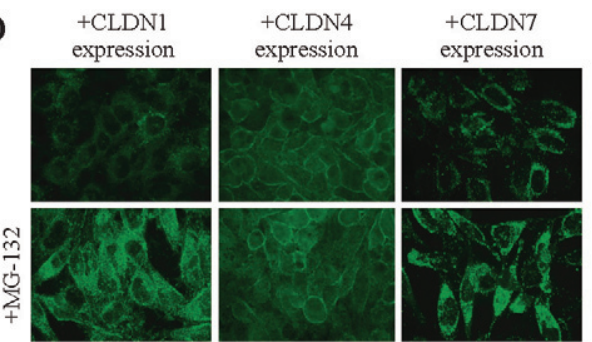

B

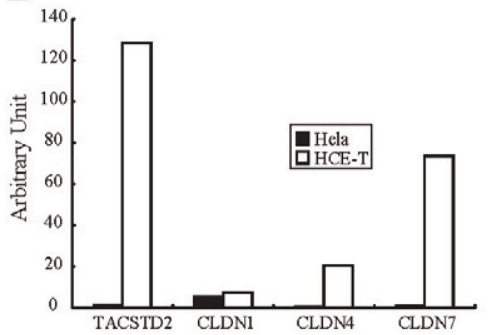
$\begin{array}{cc}\text { anti-CLDN4 } & \text { anti-CLDN7 } \\ \text { +CLDN4 expression } & \text { +CLDN7 expression }\end{array}$
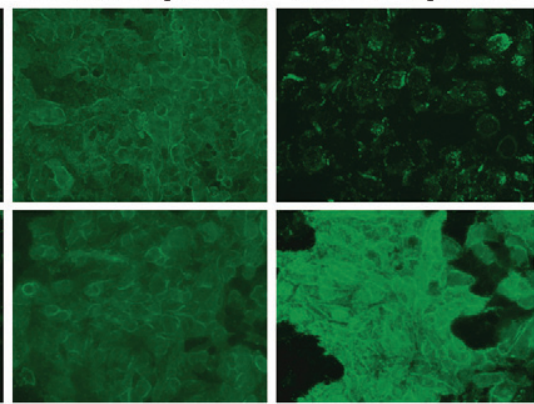

E

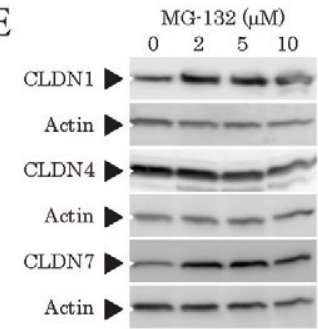

Figure 5. Effect of the forcedly expressed TACSTD2 gene in HeLa cells on the protein expression of the CLDN1, 4 , and 7 proteins. A: TER of HeLa cells was significantly low for more than two weeks after they reached confluence. B RNA expression of TJ-related proteins in HeLa cells. Compared with HCE-T-15 cells, the expression level of the TACSTD2, CLDN4, and CLDN7 proteins was significantly low in HeLa cells. C: Results of immunostaining analysis against the HeLa cells transfected with the CLDN1, 4, or 7 genes together, with or without the TACSTD2 gene, using antibodies against the TACSTD2, CLDN1, CLDN4, or CLDN7 proteins. Note that the expression level of the CLDN1 and 7 proteins in the presence of the TACSTD2 gene is significantly higher than those in the absence of the TACSTD2 gene. Original magnification was $\times 40$. D: Effect of the MG-132 treatment on the protein expression of the CLDN1, 4 , and 7 proteins. HeLa cells transfected with the CLDN1, 4 or 7 genes were treated with proteasome inhibitor MG-132 for 24 hours. Compared with the negative control, the MG-132 treatment significantly increased the expression level of the CLDN1 and 7 proteins while that of the CLDN4 protein was virtually unchanged by the MG-132 treatment. Original magnification was $\times 40$. E Effect of the MG-132 treatment on the expression of the CLDN1, 4 , and 7 proteins forcedly expressed in the HeLa cells. The MG-132 treatment significantly increased the expression level of the CLDN1 and 7 proteins in a dose-dependent manner but had virtually no effect on the expression level of the CLDN4 protein.
(Figure 6A, supplemental Figure 2A, supplemental Table 1, see http://ajp.amjpathol.org). ${ }^{23}$ As easily predicted from the results of mutation analysis showing that the patients' TACSTD2 genes bear a nonsense mutation (p.118Q $>$ X) and presumably produces a truncated TACSTD2 protein lacking a transmembrane domain (Figure $6 \mathrm{~B})$, the TACSTD2 protein was virtually absent in the GDLD corneas (Figure 6C, supplemental Figure 2B, see http://ajp.amjpathol.org). In GDLD corneas, the expression level was significantly decreased in the CLDN1, 4, and 7 proteins, and altered in their subcellular localization compared with the normal corneal epithelium (Figure 6C, supplemental Figure 2B, see $h$ ttp://ajp.amjpathol.org). TJP1 and OCLN were virtually not expressed in the GDLD corneas but were expressed at the apical side of the lateral membrane of the normal corneal epithelium (data not shown), as was found in a previous study. ${ }^{10}$ Identical results were obtained by Western blot analysis (Figure 6D). We also examined RNA expression of those TJ-related proteins in the laser-microdissected corneal epithelial cells by GPCR analysis. Corneal epithelium of GDLD expressed mRNA of the CLDN1, 4, and 7 genes at almost the same level as normal corneal epithelium (Figure 6E). This suggests that in the corneal epithelium of GDLD, the CLDN1, 4, and 7 proteins become instable and are prone to be degraded. These results were quite consistent to the results of the in vitro knockdown experiments against the TACSTD2 gene and the MG-132 treatment experiments in the CLDN 1 and 7 proteins.

\section{Association of TACSTD2 with Desmosome}

Since the tissue localization pattern of the TACSTD2 protein mimics that of desmosome, the desmosome apparatus can be another candidate for what the TACSTD2 protein functionally associates with. Double-immunostaining analysis using antibodies against the TACSTD2 protein and desmoplakin revealed an almost identical staining pattern in these two proteins, thus strongly supporting this hypothesis (supplemental Figure 3A, see http://ajp.amjpathol.org). However, immunoelectron microscopy analysis demonstrated that the subcellular localization of the TACSTD2 protein falls onto the plasma membrane but not the regions where the desmosome apparatus exists (supplemental Figure 3B, see $h t t p: / /$ ajp.amjpathol.org). In addition, in situ PLA analysis assessing the molecular proximity between the TACSTD2 protein and either of the three desmosome component proteins did not produce any significant signals (supplemental Figure 3C, see http://ajp.amjpathol.org). Therefore, we concluded that the TACSTD2 protein appears to have no spatial and functional relationship with the desmosome apparatus. 
A

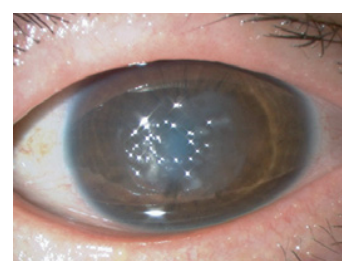

B

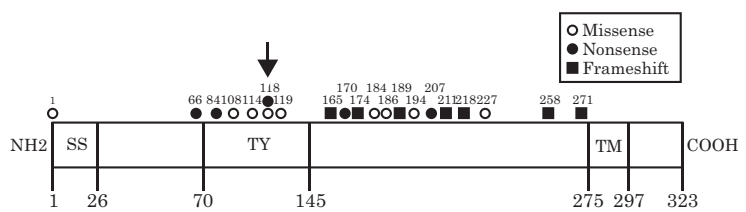

C

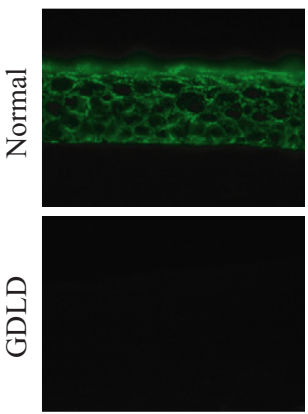

anti-CLDN1
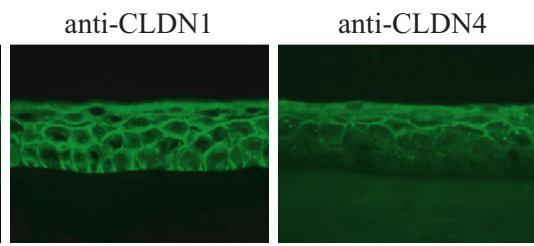

anti-CLDN7

$\mathrm{D}$

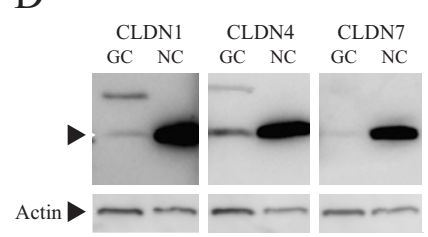

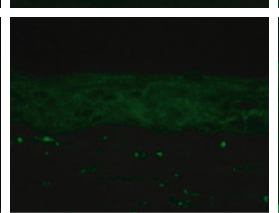

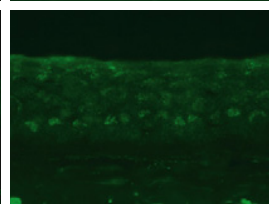

$\mathrm{E}_{2}$

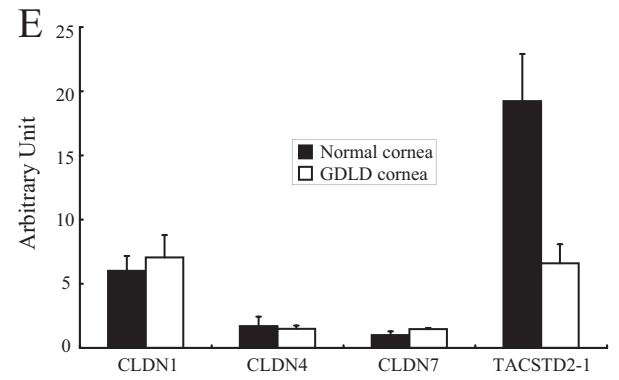

Figure 6. Expression of TJ-related proteins in the GDLD cornea. A: Clinical appearance of the cornea of a GDLD patient bearing a p.118Q $>\mathrm{X}$ nonsense mutation; grayish, protruding amyloid depositions are observed. B: Schematic representation of the structure of the TACSTD2 protein with mutations so far reported for the TACSTD2 gene indicated with amino acid numbers and types of mutation. The arrow indicates the p.118Q $>$ X nonsense mutation. "SS" means signal sequence, "TY" means thyroglobulin repeat, "TM" means transmembrane domain, and "NH2" and "COOH" mean amino and carboxy termini, respectively. C: Expression of the TACSTD2, CLDN1, 4, and 7 proteins in normal and GDLD corneas. Original magnification was $\times 40$. D: Results of Western blot analysis on the expression of CLDN1, 4, and 7 proteins in normal (NC) and GDLD corneas (GC). E: Results of qPCR analysis against the CLDN1, 4, and 7 and TACSTD2 mRNA in normal and GDLD corneas. Note that the expression level is almost identical between normal and GDLD corneas in the CLDN1, 4 , and 7 mRNA.

\section{Discussion}

The TACSTD2 gene, first cloned by Fornaro et al, ${ }^{24}$ consists of a single exon and encodes the 35,709-Da protein with a single-transmembrane domain. This gene has also been identified as a gastrointestinal tumor-associated antigen using monoclonal antibodies. ${ }^{25}$ The TACSTD2 protein is a monomeric cell surface glycoprotein ${ }^{26}$ expressed in many organs such as cornea, placenta, lung, kidney, pancreas, prostate, and in trophoblasts, ${ }^{6,27}$ and at high levels in many carcinomas. ${ }^{26,28,29}$ Although the physiological functions of this protein are still obscure, several functional domains were proposed for this molecule from its amino acid sequence. This protein contains an epidermal growth factor-like repeat, a thyroglobulin repeat, ${ }^{30,31}$ a transmembrane region, and a phosphatidylinositol 4,5-bis phosphate-binding consensus sequence. $^{32}$ It has been suggested that the TACSTD2 protein functions as a cell-to-cell adhesion receptor in cancer cells ${ }^{24}$ and as a calcium signal transducer. ${ }^{33}$

CLDNs are believed to be indispensable in forming the backbone of $\mathrm{TJ}$ and consist of $\sim 24$ members of a gene family with a molecular mass of $\sim 23 \mathrm{kDa} .{ }^{34} \mathrm{CLDNs}$ have a PDZ motif at their C-terminal region, which is thought to bind to PDZ domain-possessing proteins such as TJP1, 2, and 3 and MUPP-1. ${ }^{35,36}$ Each CLDN is expressed in a tissue- and cell-type specific fashion to achieve tissue- or cell-specific barrier function via their specific biochemi- cal properties. ${ }^{37}$ Certain cell types coexpress multiple CLDN genes and their combination and proportion vary by the types of cells. ${ }^{38}$ It is theorized that multiple CLDN proteins can polymerize into paired TJ strands in a homomeric or heteromeric manner within individual strands, and in a homotypic or heterotypic manner between opposing strands. ${ }^{39}$

We found that the TACSTD2 protein directly binds to the CLDN1 and 7 proteins. This observation is compatible with the previous report that EpCAM, a paralogous gene of the TACSTD2 gene, directly binds to the CLDN7 protein. ${ }^{20}$ The other TJ-related proteins, TJP1 and OCLN, were not coimmunoprecipitated with the TACSTD2 protein, even though we did obtain positive PLA signals between the TACSTD2 and all of the TJ-related proteins, except for the OCLN protein, in normal corneal tissues. Such discrepancy might be explained by the difference between these two experimental procedures. Immunoprecipitation is a method to examine whether two proteins are bound to each other, while the PLA assay is a method to examine whether the intermolecular distance between two proteins is short. Therefore, if two proteins reside very close to each other but do not directly bind, results might be different between the two methods. We theorize that the CLDN4 protein actually does not bind to, but closely resides to the TACSTD2 protein, maybe via a side-byside or head-to-head interaction with the CLDN1 or 7 
protein so that the intermolecular distance between the CLDN4 and TACSTD2 proteins is sufficiently short enough to be detected by PLA analysis. We also posit that the positive PLA signal found between the TACSTD2 and TJP1 proteins is also attributable to that same phenomenon.

As for the binding of the TACSTD2 protein to the CLDN1 and 7 proteins, we do not exactly know which amino acid sequence of the TACSTD2 protein is involved. However, a recent report ${ }^{19}$ has shown that the EpCAM protein binds to the CLDN7 protein through interaction between the AxxxG motifs ${ }^{40}$ that exist in their transmembrane domains. The transmembrane domain of the TACSTD2 protein is quite similar to that of the EpCAM protein with $78 \%$ identity and has the AxxxG motif at the compatible site to the EpCAM protein (Figure 7A). The CLDN1 and 7 proteins also have the AxxxG motif in their third and forth transmembrane domains, while the CLDN4 protein does not have the AxxxG motif in any of its 4 transmembrane domains (Figure 7B). Therefore, this strongly suggests that the TACSTD2 protein and either of the CLDN1 and 7 proteins bind to each other through their AxxxG motifs. In addition, absence of the AxxxG motif in the transmembrane domains of the CLDN4 protein may account for our immunoprecipitation results showing that the CLDN4 protein does not bind to the TACSTD2 protein. Sequence comparison against the entire coding sequences of 22 members of the CLDN gene family (Figure $7 \mathrm{C}$ ) also revealed that the CLDN1 and 7 proteins have a similar amino acid sequence, while the CLDN4 protein has a quite different amino acid sequence from these two proteins, thus coinciding with our observation that the CLDN1 and 7 proteins exhibit a similar
A

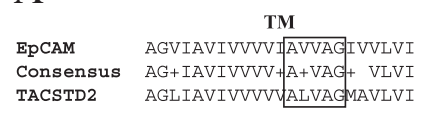

$\mathrm{C}$

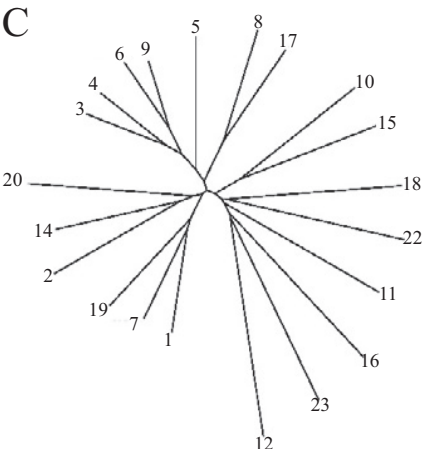

B

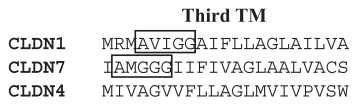

Forth TM

CLDN1 ALFTGNAAASLCLLGGALLCC CLDN7 FGPAIFIGNAGSALVILGGAL CLDN4 GASLYVGWAASGLLLLGGGLI
Figure 7. Sequence comparison between the TACSTD2 and the EPCAM proteins and among the CLDN1, 4, and 7 proteins in their transmembrane domains. A: Both the TACSTD2 and the EpCAM proteins have an AxxxG motif (enclosed by a square) in their transmembrane (TM) domain. B: CLDN1 and 7 proteins have 2 AxxxG motifs in their third and forth transmembrane domains, while the CLDN4 protein does not have an AxxxG motif in any of its 4 transmembrane domains. C: Schematic representation of a molecular phylogenetic tree among 22 members of the CLDN gene family depicted in an unrooted N-J tree image. Note that the CLDN1 and 7 genes are quite similar over their entire coding regions while the CLDN 4 gene is quite different from these two genes. biochemical and cytological behavior to each other, while the CLDN4 did not.

It is still unclear how the TACSTD2 protein functionally associates with the CLDN1 and 7 proteins. There seem to be at least three possibilities. First, the TACSTD2 protein acts as an anchor protein for the proper localization of the CLDN proteins at the plasma membrane. Second, the TACSTD2 protein stabilizes and prevents the CLDN proteins from degradation. Third, the TACSTD2 protein acts as a transporter in the membrane trafficking process of the CLDN proteins. We think that our time-course data in the TACSTD2 knockdown experiments may shed a light on the answers. Four days after the lentiviral infection, the TACSTD2 protein was significantly knocked down while all of the examined TJ-related proteins were virtually not affected, both in their expression level and subcellular localization. However, seven days after the infection, the expression level of the CLDN1 and 7 proteins were decreased along with altered subcellular localization in all of the TJ-related proteins examined in this study. These results may be discrepant to the first possibility, yet they do seem to be concordant with the second or third possibility. The results of the MG-132 treatment experiment strongly support the second possibility, but we feel that the third possibility is still likely since the ablation of the TACSTD2 gene in HCE-T cells altered the subcellular localization of the CLDN1 and 7 proteins. Further experiments will be needed to fully uncover the exact mechanism.

In summary, our current study has unveiled the yetunlinked pieces of the puzzle between the loss of function mutation of the TACSTD2 gene and the decreased epithelial barrier function in GDLD corneas. The pathological processes that occur in GDLD corneas appear to be that mutation of the TACSTD2 gene firstly causes the loss of function of this protein, secondly leads to decreased expression and altered subcellular localization of the CLDN proteins, thirdly causes decreased expression and altered subcellular localization of the TJP1 and the OCLN proteins, and finally causes significant impairment in the formation and maturation of the TJ. Although we currently do not have any information for other types of epithelia than corneal epithelium, we theorize that the TACSTD2 gene has a general role in the formation of the $\mathrm{TJ}$ over a broad spectrum of the stratified epithelia. However, it is still unclear why organs other than the cornea that are covered by stratified epithelia do not demonstrate the disease phenotype in GDLD patients. This question should be considered as the next major challenge to be thoroughly resolved for the complete understanding of the pathogenesis of GDLD. We hope that our current study will contribute to future investigations aimed at an improved understanding the pathogenesis of GDLD, as well as the development of better treatments for this disease.

\section{Acknowledgment}

We thank John Bush for reviewing the manuscript. 


\section{References}

1. Nakaizumi G: A rare case of corneal dystrophy. Acta Soc Ophthalmol Jpn 1914, 18:949-950

2. Fujiki K, Kanai A, Nakajima A: Gelatinous drop-like corneal dystrophy in Japanese population (abstract). 7th Int. Cong. Hum. Genet. 1986, 248-249

3. Kawano H, Fujiki K, Kanai A, Nakajima A: Prevalence of gelatinous drop-like corneal dystrophy in Japan. Atarashii Ganka 1992, 9:1879_ 1882

4. Weber FL, Babel J: Gelatinous drop-like dystrophy: a form of primary corneal amyloidosis. Arch Ophthalmol 1980, 98:144-148

5. Mondino BJ, Rabb MF, Sugar J, Sundar Raj CV, Brown SI: Primary familial amyloidosis of the cornea. Am J Ophthalmol 1981, 92: 732-736

6. Tsujikawa M, Kurahashi H, Tanaka T, Nishida K, Shimomura Y, Tano $Y$, Nakamura Y: Identification of the gene responsible for gelatinous drop-like corneal dystrophy. Nat Genet 1999, 21:420-423

7. Tsujikawa M, Kurahashi H, Tanaka T, Okada M, Yamamoto S, Maeda $\mathrm{N}$, Watanabe $\mathrm{H}$, Inoue $\mathrm{Y}$, Kiridoshi $\mathrm{A}$, Matsumoto $\mathrm{K}$, Ohashi $\mathrm{Y}$, Kinoshita S, Shimomura Y, Nakamura Y, Tano Y: Homozygosity mapping of a gene responsible for gelatinous drop-like corneal dystrophy to chromosome 1p. Am J Hum Genet 1998, 63:1073-1077

8. Kinoshita S, Nishida K, Dota A, Inatomi T, Koizumi N, Elliott A, Lewis D, Quantock A, Fullwood N: Epithelial barrier function and ultrastructure of gelatinous drop-like corneal dystrophy. Cornea 2000, 19: 551-555

9. Quantock AJ, Nishida K, Kinoshita S: Histopathology of recurrent gelatinous drop-like corneal dystrophy. Cornea 1998, 17:215-221

10. Takaoka M, Nakamura T, Ban Y, Kinoshita S: Phenotypic investigation of cell junction-related proteins in gelatinous drop-like corneal dystrophy. Invest Ophthalmol Vis Sci 2007, 48:1095-1101

11. Klintworth GK, Sommer JR, Obrian G, Han L, Ahmed MN, Qumsiyeh MB, Lin PY, Basti S, Reddy MK, Kanai A, Hotta Y, Sugar J, Kumaramanickavel G, Munier F, Schorderet DF, El Matri L, Iwata F, Kaiser-Kupfer M, Nagata M, Nakayasu K, Hejtmancik JF, Teng CT: Familial subepithelial corneal amyloidosis (gelatinous drop-like corneal dystrophy): exclusion of linkage to lactoferrin gene. Mol Vis 1998, 4:31-38

12. Klintworth GK, Valnickova Z, Kielar RA, Baratz KH, Campbell RJ, Enghild JJ: Familial subepithelial corneal amyloidosis - a lactoferrinrelated amyloidosis. Invest Ophthalmol Vis Sci 1997, 38:2756-2763

13. Nishida K, Quantock AJ, Dota A, Choi-Miura NH, Kinoshita S: Apolipoproteins $\mathrm{J}$ and $\mathrm{E}$ co-localise with amyloid in gelatinous drop-like and lattice type I corneal dystrophies. $\mathrm{Br} J$ Ophthalmol 1999 83:1178-1182

14. Araki-Sasaki K, Ohashi Y, Sasabe T, Hayashi K, Watanabe H, Tano Y, Handa H: An SV40-immortalized human corneal epithelial cell line and its characterization. Invest Ophthalmol Vis Sci 1995, 36:614-621

15. Ebato B. Friend J, Thoft RA: Comparison of central and peripheral human corneal epithelium in tissue culture. Invest Ophthalmol Vis Sci 1987, 28:1450-1456

16. Yamasaki K, Kawasaki S, Young RD, Fukuoka $H$, Tanioka $H$, Nakatsukasa M, Quantock AJ, Kinoshita S: Genomic aberrations and cellular heterogeneity in SV40-immortalized human corneal epithelial cells. Invest Ophthalmol Vis Sci 2009, 50:604-613

17. Szala S, Froehlich M, Scollon M, Kasai Y, Steplewski Z, Koprowski H, Linnenbach AJ: Molecular cloning of cDNA for the carcinoma-associated antigen GA733-2. Proc Natl Acad Sci USA. 1990, 87:3542-3546

18. Strnad J, Hamilton AE, Beavers LS, Gamboa GC, Apelgren LD, Taber LD, Sportsman JR, Bumol TF, Sharp JD, Gadski RA: Molecular cloning and characterization of a human adenocarcinoma/epithelial cell surface antigen complementary DNA. Cancer Res 1989, 49:314-317

19. Nubel T, Preobraschenski J, Tuncay H, Weiss T, Kuhn S, Ladwein M, Langbein L, Zoller M: Claudin-7 regulates EpCAM-mediated functions in tumor progression. Mol Cancer Res 2009, 7:285-299

20. Ladwein M, Pape UF, Schmidt DS, Schnolzer M, Fiedler S, Langbein L, Franke WW, Moldenhauer G, Zoller M: The cell-cell adhesion molecule EpCAM interacts directly with the tight junction protein claudin-7. Exp Cell Res 2005, 309:345-357

21. Kuhn S, Koch M, Nubel T, Ladwein M, Antolovic D, Klingbeil P, Hildebrand D, Moldenhauer G, Langbein L, Franke WW, Weitz J, Zoller M: A complex of EpCAM, claudin-7. CD44 variant isoforms, and tetraspanins promotes colorectal cancer progression. Mol Cancer Res 2007, 5:553-567

22. Yoshida $Y$, Ban $Y$, Kinoshita S: Tight junction transmembrane protein claudin subtype expression and distribution in human corneal and conjunctival epithelium. Invest Ophthalmol Vis Sci 2009, 50:2103-2108

23. Ide T, Nishida K, Maeda N, Tsujikawa M, Yamamoto S, Watanabe H, Tano Y: A spectrum of clinical manifestations of gelatinous drop-like corneal dystrophy in Japan. Am J Ophthalmol 2004, 137:1081-1084

24. Fornaro M, Dell'Arciprete R, Stella M, Bucci C, Nutini M, Capri MG, Alberti S: Cloning of the gene encoding Trop-2, a cell-surface glycoprotein expressed by human carcinomas. Int J Cancer 1995, 62:610-618

25. Sears HF, Herlyn D, Steplewski Z, Koprowski H: Effects of monoclonal antibody immunotherapy on patients with gastrointestinal adenocarcinoma. J Biol Response Mod 1984, 3:138-150

26. Alberti S, Miotti S, Stella M, Klein CE, Fornaro M, Menard S, Colnaghi MI: Biochemical characterization of Trop-2, a cell surface molecule expressed by human carcinomas: formal proof that the monoclonal antibodies T16 and MOv-16 recognize Trop-2. Hybridoma 1992 11:539-545

27. Lipinski M, Parks DR, Rouse RV, Herzenberg LA: Human trophoblast cell-surface antigens defined by monoclonal antibodies. Proc Natl Acad Sci USA. 1981, 78:5147-5150

28. Fradet $Y$, Cordon-Cardo C, Thomson T, Daly ME, Whitmore WF Jr, Lloyd KO, Melamed MR, Old LJ: Cell surface antigens of human bladder cancer defined by mouse monoclonal antibodies. Proc Nat Acad Sci USA 1984, 81:224-228

29. Miotti S, Canevari S, Menard S, Mezzanzanica D, Porro G, Pupa SM Regazzoni M, Tagliabue E, Colnaghi MI: Characterization of human ovarian carcinoma-associated antigens defined by novel monoclonal antibodies with tumor-restricted specificity. Int J Cancer 1987, 39:297-303

30. Kiefer MC, Masiarz FR, Bauer DM, Zapf J: Identification and molecular cloning of two new 30-kDa insulin-like growth factor binding proteins isolated from adult human serum. J Biol Chem 1991 266:9043-9049

31. Malthiery $Y$, Lissitzky S: Primary structure of human thyroglobulin deduced from the sequence of its 8448-base complementary DNA Eur J Biochem 1987, 165:491-498

32. El Sewedy T, Fornaro M, Alberti S: Cloning of the murine TROP2 gene: conservation of a PIP2-binding sequence in the cytoplasmic domain of TROP-2. Int J Cancer 1998, 75:324-330

33. Ripani E, Sacchetti A, Corda D, Alberti S: Human Trop-2 is a tumorassociated calcium signal transducer. Int J Cancer 1998, 76:671-676

34. Morita K, Furuse M, Fujimoto K, Tsukita S: Claudin multigene family encoding four-transmembrane domain protein components of tight junction strands. Proc Natl Acad Sci USA. 1999, 96:511-516

35. Hamazaki Y, Itoh M, Sasaki H, Furuse M, Tsukita S: Multi-PDZ domain protein 1 (MUPP1) is concentrated at tight junctions through its possible interaction with claudin-1 and junctional adhesion molecule. J Biol Chem 2002, 277:455-461

36. Itoh M, Furuse M, Morita K, Kubota K, Saitou M, Tsukita S: Direct binding of three tight junction-associated MAGUKs. ZO-1, ZO-2, and ZO-3, with the COOH termini of claudins. J Cell Biol 1999, 147:13511363

37. Rahner C, Mitic LL, Anderson JM: Heterogeneity in expression and subcellular localization of claudins $2,3,4$, and 5 in the rat liver pancreas, and gut. Gastroenterology 2001, 120:411-422

38. Furuse M, Tsukita S: Claudins in occluding junctions of humans and flies. Trends Cell Biol 2006, 16:181-188

39. Furuse M, Sasaki H, Tsukita S: Manner of interaction of heterogeneous claudin species within and between tight junction strands. J Cell Biol 1999, 147:891-903

40. Kleiger G, Grothe R, Mallick P, Eisenberg D: GXXXG and AXXXA: common $\alpha$-helical interaction motifs in proteins, particularly in extremophiles. Biochemistry 2002, 41:5990-5997 